\title{
Dynamics Modeling and Simulation Analysis of the Vertical Machining Center Dual-drive Feed System
}

\author{
Mingde Duan ${ }^{1, a}$, Haichao Zang ${ }^{1, b^{*}}$, Jing Dai $^{1, c}$, \\ Zhuangya Zhang ${ }^{1, \mathrm{~d}}$ and Hezeng Wang ${ }^{2, \mathrm{e}}$ \\ ${ }^{1}$ School of Mechatronic Engineering, Henan University of Science and Technology, Luoyang, \\ 471003, China \\ ${ }^{2}$ YTO (Luoyang) KINTRA Equipment Science \& Technology Co. Ltd., Luoyang, 471003, China \\ ${ }^{3}$ List all distinct addresses in the same way \\ aduan_mingde@163.com, bhc19921021@163.com, 'cdaijing1121@163.com, \\ dzhangzhuangya@126.com, "whz196610@163.com \\ * The corresponding author
}

Keywords: Vertical machine center; Dual-drive feed system; Spindle box weight; Output torque; Control parameters

\begin{abstract}
In order to improve the dynamic performance of the dual-drive feed system of vertical CNC machine tools, according to the vertical machine center KSMC1250 Y axis dual-drive feed system for the study, based on the d Alembert's principle of mechanical dynamics, contained the bearing friction torque, guide friction, backlash and other facts, the model of dual-drive feed system was established. The Matlab/Simulink simulation model is established by using numerical simulation method, the paper analyzed the influence of spindle box weight, the output torque of servo motor, the position parameters of gravity center and the control parameters on the feed system. The results showed that the spindle box weight and the servo motor output torque affected the spindle box feed speed, the position loop gain and speed adjusting gain affected the spindle box to achieve uniform time, while the position of gravity center parameters of spindle box spindle box had little influence on running speed. The conclusion of the study provided a theoretical basis for the design of the vertical CNC machine feed system.
\end{abstract}

\section{Introduction}

With the request for overall performance of CNC machine tools increasing, CNC machine tools is developing rapidly in high precision, high speed, high efficiency, high reliability and other aspects. Double-drive feed system has characteristics of high speed and acceleration. It can achieve the system's rapid feed, improving processing efficiency. In references [1-2], the mathematical model of the single-axle feed system is established, and the influence of friction, gap and other factors on the feeding system is studied. In references [3-4], the dual-axis synchronous control model is established to study the effect of biaxial coupling, two-axis friction and center-of-gravity change on the non-synchronous error. In references [5-6], the dual-drive system is used as the research object, and the dynamic characteristics of the feeding system are studied by using the finite element method. In references [7-8], on the basis of the study of double-drive feed system, the system parameters are identified and the control model is established. The above scholars have made great progress in the research of the CNC feed system, but the research on the overall dynamic characteristics of the CNC feed system is little. In this paper, the Y-axis feed system of KSMC1250 vertical machining center is used as the research object, and the mechanical dynamic analysis method is used to analyze the feed system. The mathematic model of mechanical-electric coupling is established considering the friction torque of the bearing and coulomb friction and viscous friction coupling caused by the center of gravity of the spindle box. The influence factors of the dynamic characteristics of the feed system are studied by Matlab/Simulink simulation. 


\section{Establishment of Mathematical Model of Y-axis Feeding System}

Description and Simplification of Feed System Model. In this paper, the Y-axis feed system of KSMC1250 vertical machining center is shown in Fig. 1, and the feed system is driven through two sets of ball screw drive. Permanent magnet AC servo motor is driven by the belt, and the power is transfered to the ball screw. Through the ball screw nut's drive, the rotary motion is converted into a linear motion, driving the spindle box up and down to move. Servo feed system uses closed-loop synchronous control. The scale is installed in the spindle box, measuring the spindle box displacement signal, and the signal is feed-backed to the servo control system. In Fig. 1: 1 is the column, 2 is the servo motor; 3 is the pulley $1 ; 4$ is the timing belt; 5 is the pulley 2; 6 is the bearing assembly; 7 is the linear guide; 8 is the ball screw; 9 is the screw nut pair ; 10 is the spindle box parts.

Model simplification: Based on the $\mathrm{Y}$-axis feed system, ignoring the deviation between the motor shaft and the pulley 1 and the angular deviation of the pulley 2 and the lead screw, using the timing belt transfer efficiency $\eta$ to simulate the power transmission relationship between the pulley 1 and pulley 2. Taking into account the friction torque of the bearing, rail friction, the gap between the ball screw and the steady bearing and the bearing assembly clearance are taken into account the screw nut drive gap, and the two ball screw drive brings the synchronization error is ignored. The spindle box component is simplified as a mass $\mathrm{M}$, and the biaxial transmission is regarded as two uniaxial drives for dynamic coupling, and the simplified mechanical model is established like Fig. 2. In Fig. 2: $T_{p l}$ is the load torque of pulley $1, r_{1}$ is the radius of pulley $1, T_{p 2}$ is the load torque of pulley $2, r_{2}$ is the radius of pulley 2, $\theta_{m}$ is servo motor angular displacement, $\theta_{s}$ is the ball screw angular displacement, $T_{f}$ is the total friction torque of bearing and screw nut drive, $T_{n}$ is the ball screw load torque, $K_{e}$ is integrated axial drive stiffness, $x_{s}$ is the screw output theoretical displacement, $x_{t}$ is the spindle box actual displacement, $m$ is the mass of spindle box , $F_{z}$ is the screw drive force, $f_{z}$ is the rail friction.

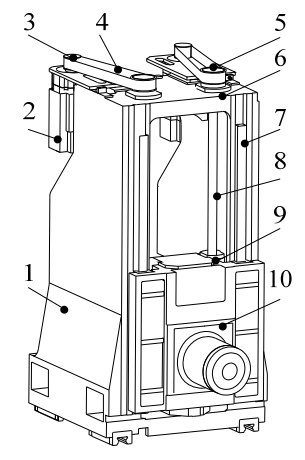

Figure 1. Y-axis feed system

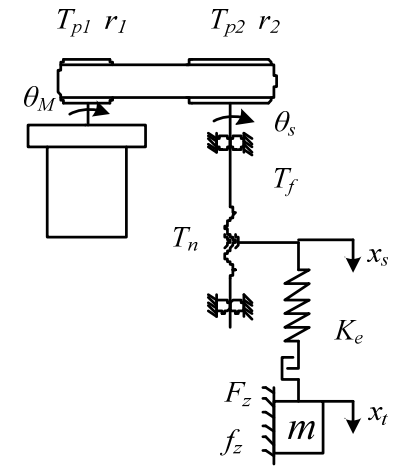

Figure 2. Simplified model

Establish of mathematical model of Servo Feeding System. The closed loop PID control system is appropriately simplified, and the input signal command passes through the loop gain and signal feedback to obtain the mathematical equation

$$
L \dot{I}+R I=K_{i p}\left[K_{v p}\left(K_{p p} K_{v} e-\dot{\theta}_{m}\right)-\mathrm{I}\right]-K_{\text {enf }} \dot{\theta}_{m}
$$

Where, $e$ is the spindle box displacement error, $e=x_{s}-x_{t} ; L$ is the servo motor magnetic field inductance, $R$ is the servo motor resistance, $K_{i p}$ is the current loop gain, $K_{v p}$ is the speed loop gain, $K_{p p}$ is the position loop gain , $K_{v}$ is the speed loop command to adjust the gain, $K_{\text {emf }}$ is the back-EMF for electromotor.

The servo motor controls the output torque via the PID, transmits the torque to the pulley 1 , and the pulley 1 is driven to the pulley 2 via the timing belt

$$
\begin{aligned}
& T_{m}=K_{t} I \\
& T_{m}-T_{p 1}-C_{m} \dot{\theta}_{m}=\left(J_{m}+J_{p 1}\right) \ddot{\theta}_{m}
\end{aligned}
$$




$$
\begin{aligned}
& i=r_{2} / r_{1} \\
& T_{p 2}=\eta T_{p 1} i \\
& \theta_{m}=i \theta_{s}
\end{aligned}
$$

Where, $K_{t}$ is the servo motor torque coefficient, $T_{m}$ is the servo motor output torque, $C_{m}$ is the servo motor viscous damping coefficient, $J_{m}$ is the servo motor moment of inertia, $J_{p 1}$ is the pulley 1 moment of inertia, $i$ is the belt transmission ratio, $\eta$ is the efficiency for belt.

Model of ball screw drive

$$
\begin{aligned}
& T_{p 2}-T_{f}-T_{n}-C_{s} \dot{\theta}_{s}=\left(J_{p 2}+J_{s}\right) \ddot{\theta}_{s} \\
& T_{n}=\xi F_{Z} \\
& \xi=P_{h} / 2 \pi
\end{aligned}
$$

Where, $J_{p 2}$ is the moment of inertia for pulley 2, $C_{s}$ is the viscous damping coefficient for ball screw, $\xi$ is the transmission ratio for rotation movement and linear motion, $P_{h}$ is the lead.

Model of spindle box coupling motion

$$
F_{z}=K_{e}\left(x_{s}-x_{t}\right)
$$

$\left(F_{z 1}-f_{z 1}\right)+\left(F_{z 2}-f_{z 2}\right)-m g-C_{t} \dot{x}_{t}=m \ddot{x}$

Where, $F_{z 1}, F_{z 2}$ are 1 axis and 2 axis drive force, $f_{z 1}, f_{z 2}$ are 1 axis and 2 axis rail friction, $C_{r}$ is the moving viscous damping for the rail, $g$ is the gravity acceleration.

The integrated axial drive stiffness $K_{e}$ is solved by axial stiffness and torsional stiffness

$\frac{1}{K_{e}}=\frac{1}{K_{1}}+\frac{\xi^{2}}{K_{2}}$

Where, $K_{1}$ is the axial stiffness, $K_{2}$ is the torsional stiffness for the ball screw

$\frac{1}{K_{1}}=\frac{1}{K_{s}}+\frac{1}{K_{n}}+\frac{1}{K_{b}}+\frac{1}{K_{h}}$

Where, $K_{s}$ is the axial stiffness of ball screw, $K_{n}$ is the axial stiffness, $K_{b}$ is the axial stiffness for bearing, $K_{h}$ is the axial stiffness for bearing support and nut support.

Friction for Feed System. Total friction torque of bearing and screw nut drive.

The friction torque of the bearing is calculated according to Palmgren's experience

$$
M=M_{0}+M_{1}
$$

Where, $M_{0}$ is the friction torque associated with the bearing type, the nature of the lubricant and the speed, $M_{1}$ is the friction torque associated with the bearing load.

Due to $v n \geq 2000$,

$$
\begin{aligned}
& M_{0}=10^{-7} f_{0}(v n)^{\frac{2}{3}} D_{m}{ }^{3} \\
& M_{1}=f_{1} F_{\beta} D_{m} \\
& f_{1}=z\left(P_{0} / C_{a}\right)^{y}
\end{aligned}
$$

Where, $f_{0}$ is the coefficient associated with bearing lubrication method, $D_{m}$ is the the bearing diameter, $v$ is the kinematic viscosity of the bearing lubricant, $n$ is the bearing speed. $f_{l}$ is the coefficient associated with bearing load and type, $F_{\beta}$ is the bearing working load, $P_{0}$ is the equivalent 
static load of bearing, $C_{a}$ is the rated static load of bearing, $z, y$ is the coefficient related to the bearing type.

Calculation of friction moment of screw nut

$$
T_{s}=0.05(\tan \beta)^{-0.5} \frac{F_{z} P_{h}}{2 \pi}
$$

Where, $\underline{T}_{S}$ is the nut friction torque, $\beta$ is the lead angle of screw, $F_{z}$ is the screw nut load.

The total friction torque of the bearing and the screw nut drive

$$
T_{f}=M+T_{s}
$$

Fig. 3 shows that when the spindle box moves, the load acting on the rolling rail can be estimated to the spindle box' Coulomb friction, and then by the rail movement of the viscous friction coefficient, a rail friction model can be established.

$$
\begin{aligned}
& P_{1}=P_{4}=-\frac{m(g+a) L_{2}}{2 L_{0}} \\
& P_{2}=P_{3}=\frac{m(g+a) L_{2}}{2 L_{0}} \\
& P_{1 t}=P_{4 t}=\frac{m(g+a) L_{3}}{2 L_{0}} \\
& P_{2 t}=P_{3 t}=-\frac{m(g+a) L_{3}}{2 L_{0}} \\
& f_{z}=P \mu
\end{aligned}
$$

Where, $P_{n}, P_{n T}$ is the load applied to the rolling guide, $L_{0}$ is the distance between the two gliding block for rails, $L_{1}$ is the distance between the rails, $L_{2}$ is the distance from the center of the table to the rail, $L_{3}$ is the distance from center of gravity of the table to the central plane of the two rails, $F_{z}$ is driving force of the screw for the two shafts, $f_{z 1}, f_{z 2}$ for the rails of the Cullen friction.

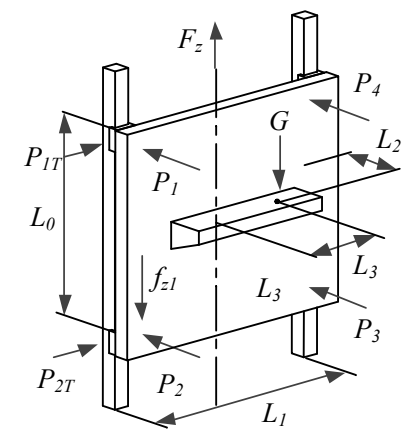

Figure 3. The force diagram of the rail

\section{Establishment of Simulation Model}

According to the mathematical model established above and according to the formulas (1) to (24), the simulation model is established as shown in Fig. 4. In this paper, the parameters of KSMC1250 are as an example to simulate. The servo motor inductance $L$ is $0.91 \mathrm{mH}$, motor resistance $R$ is $1 \Omega$, the motor back EMF constant $K_{\text {emf }}$ is 0.2 , current loop gain $K_{i p}$ is 7, speed loop gain $K_{v p}$ is 10, position loop gain $K_{p p}$ is 2, motor torque constant $K_{t}$ is 1.43 , motor viscous damping coefficient $C_{m}$ is 0.004 , motor moment of inertia $J_{m}$ is $178 \times 10^{-4} \mathrm{~kg} \cdot \mathrm{m}^{2}$, moment of inertia of pulley $1 J_{p 1}$ is $30 \times 10^{-4} \mathrm{~kg} \cdot \mathrm{m}^{2}$, wheel inertia $J_{p 1}$ is $17 \times 10^{-4} \mathrm{~kg} \cdot \mathrm{m}^{2}$, screw lead $P_{h}$ is $25 \mathrm{~mm}$, integrated axial stiffness $K_{e}$ is $142.62 \times 10^{-6} \mathrm{~N} \cdot \mathrm{m}^{-1}$, 
bearing diameter $D_{m}$ is $65 \mathrm{~mm}$, bearing rated static load $C_{a}$ is $95500 \mathrm{~N}$, the coefficient associated with the bearing model $z$ is $0.001, y$ is 0.33 , nut preload load $F_{n y}$ is $980 \mathrm{~N}$.

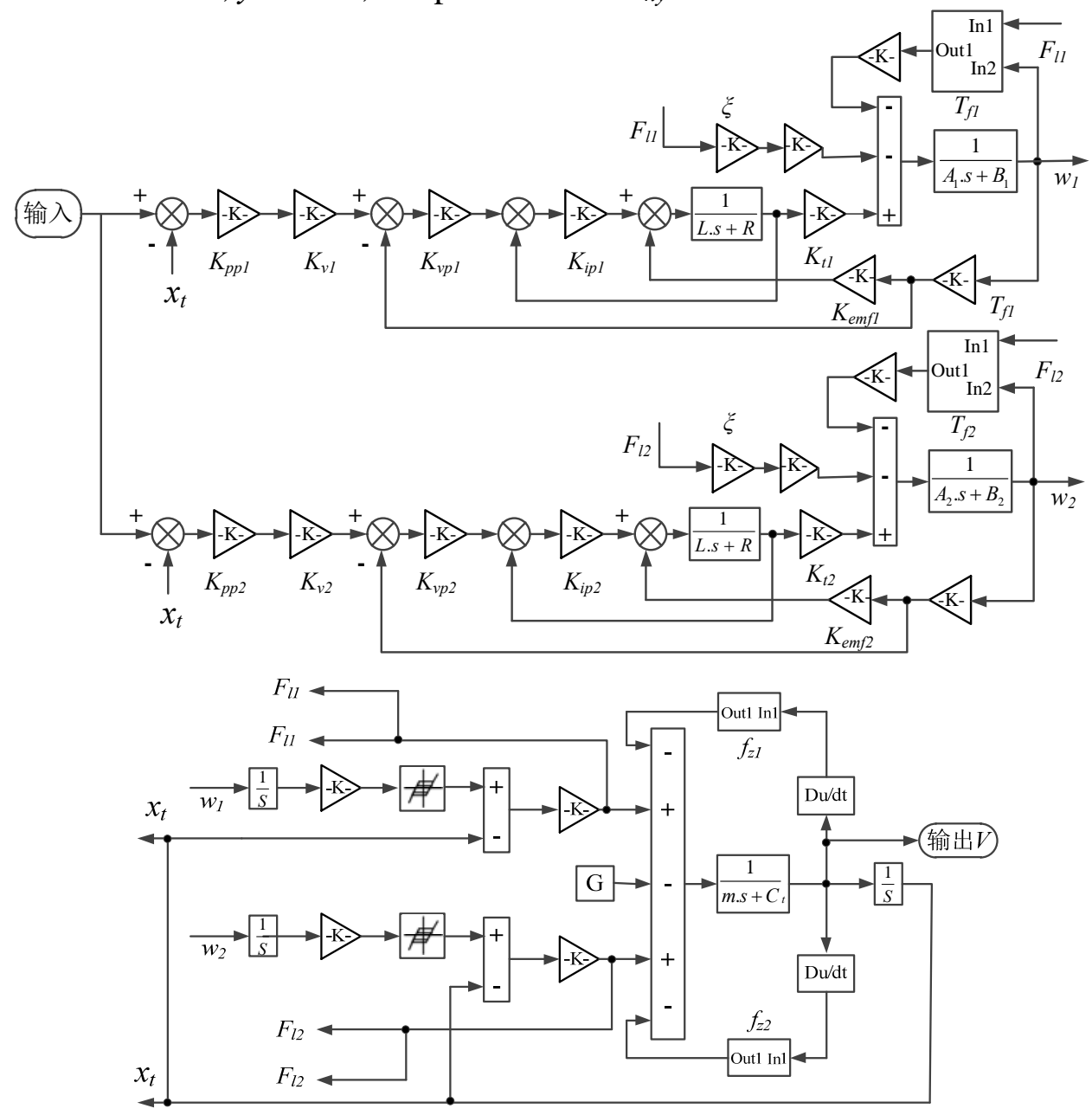

Figure 4. Simulink simulation model of double drive feed system

\section{Simulation Analysis of Feed System}

The Influence of the Weight of the Spindle Box on the Speed. The spindle unit of the vertical machining center consists of the main shaft motor, the shift gear, the spindle part and the main shaft box. So its overall weight is heavy, and greatly affect the dynamic characteristics of the vertical processing center $\mathrm{Y}$-axis feed system. In this paper, when the permanent torque servo motor to starts in constant torque, permanent magnet servo motor output torque $\mathrm{T}$ is $30 \mathrm{~N} \cdot \mathrm{m}$. When the mass of the spindle box components is selected by $1300 \mathrm{~kg}, 1170 \mathrm{~kg}$ and $1040 \mathrm{~kg}$ respectively, the feed system is dynamically simulated, the $V$ - $t$ curve of the movement of the spindle box is got. As can be seen from Fig. 5, the smaller the quality of the spindle box components is, the faster the speed increase and the speed at which uniform motion is reached is greater. If the motion of the first $5 \mathrm{~s}$ is approximately constant acceleration, the acceleration increases by $18.6 \%$ and $44.5 \%$ respectively when the mass is reduced by $10 \%$ and $20 \%$ from $1300 \mathrm{~kg}$, respectively. It shows that the mass of the spindle part has an important influence on the dynamic characteristics of the whole feeding system. 


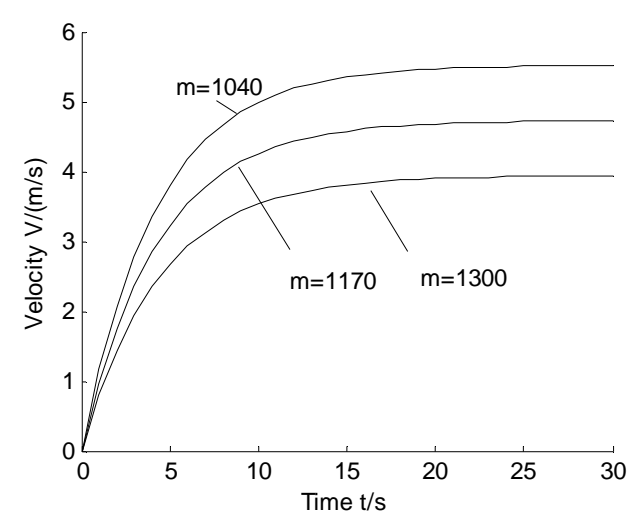

Figure 5. Influence of the weight of the spindle box on the feed system

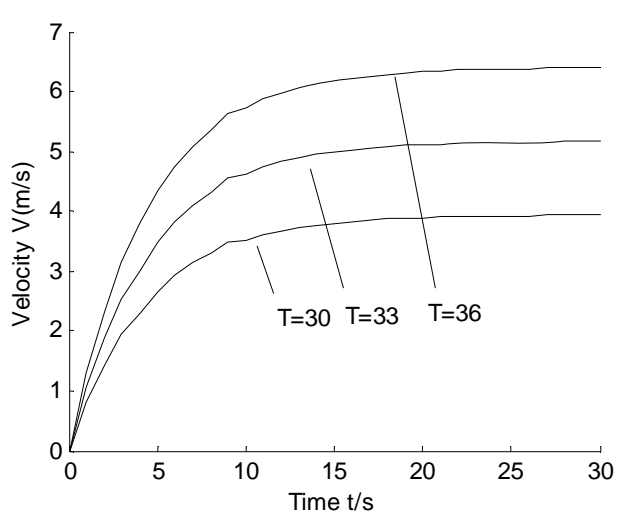

Figure 6. Influence of servo motor output torque on feeding system

The Effect of Input Torque on Speed. The output torque of the permanent magnet servo motor plays an important role in the movement of the whole spindle case. When the overall structure of the feed system is designed, the servo motor needs to be selected and matched with the structural parameters of the whole feeding system to achieve the overall power design requirements. When the output torque $\mathrm{T}$ of the permanent magnet servo motor is $30 \mathrm{~N} \cdot \mathrm{m}, 33 \mathrm{~N} \cdot \mathrm{m}$ and $36 \mathrm{~N} \cdot \mathrm{m}$, the $\mathrm{V}$-t curve of the spindle box part is obtained. As can be seen from Fig. 6, the final speed of the spindle unit increases as the output torque of the servomotor increases. If the motion of the front $5 \mathrm{~s}$ is approximated as a constant acceleration motion, the acceleration of the first $5 \mathrm{~s}$ can be increased by $34.6 \%$ and $65.3 \%$ respectively when the output torque of the servo motor is increased by $10 \%$ and $20 \%$ from $30 \mathrm{~N} \cdot \mathrm{m}$. Therefore, the output torque of the servo motor has an important influence on the kinetic characteristic of the spindle box. When the feeding system is designed, the servo motor corresponding to the feed structure should be properly selected to meet the power design requirements of the feed system.

Effect of Center Position Parameter on Speed. According to equations (20) to (24), the two design parameters of $L_{2}$ and $L_{3}$ affect the Coulomb friction of the guide rail, which then affects the feed rate of the spindle box components. When the other parameters are not changed and the output torque of the servo motor $\mathrm{T}$ is $30 \mathrm{~N} \cdot \mathrm{m}$, the appropriate different parameters are selected by $L_{2}$ and $L_{3}$ respectively, and the $V$ - $t$ curve is obtained respectively.

As can be seen from Fig. 7, as the $L_{2}$ increases, the frictional force increases and the velocity decreases faintly. The excessive $L_{2}$ will cause the spindle housing component to affect the center of gravity offset, which is not conducive to the coordinated motion of the biaxial feed system. As the $L_{3}$ increases, the rail friction increases and the speed is weakly reduced. So the design should be as far as possible so that the longitudinal axis of the spindle position and the screw is similar.

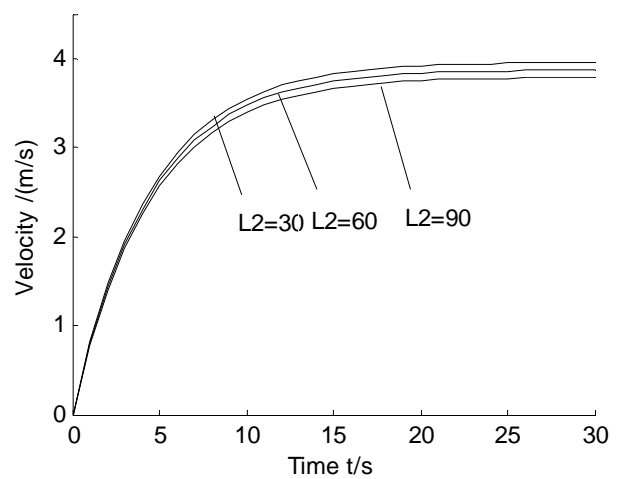

Figure 7. The influence of center of gravity parameter $L_{2}$ on feed system

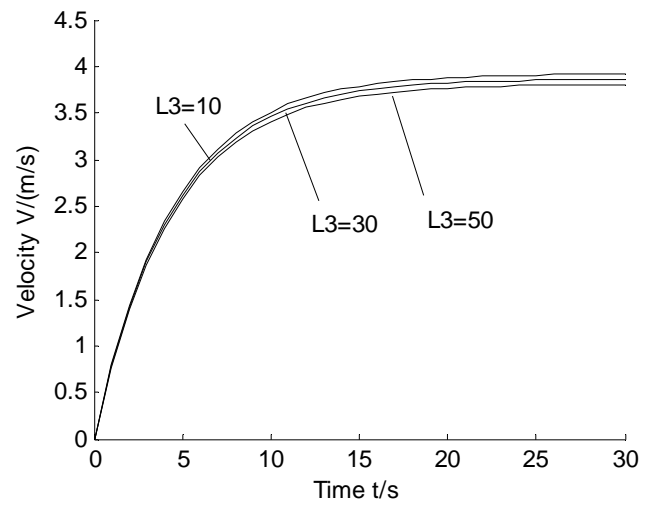

Figure 8. The influence of center of gravity parameter $L_{3}$ on feed system 
The Influence of the Control Parameters of the Servo Motor on the Speed. As the important part of the CNC machine tool, the servo system has important influence on the feed performance of the machine. In this paper, the position loop gain, the speed loop adjustment gain, the speed loop gain and the current loop gain are taken as the variables, and the slope signal is used as input It is found that the position loop gain and velocity loop gain have an important influence on whether the system can reach the uniform speed quickly. It can be seen from Fig. 9 and Fig. 10 that when the position loop gain $K_{p p}$ is 1, 5, 10 and the speed adjustment gain $K_{v}$ is 100, 200 and 300, the time which the spindle box reaches a uniform speed becomes shorter. The proper increase in position loop gain and speed adjustment gain can improve the motion characteristics of the feed system.

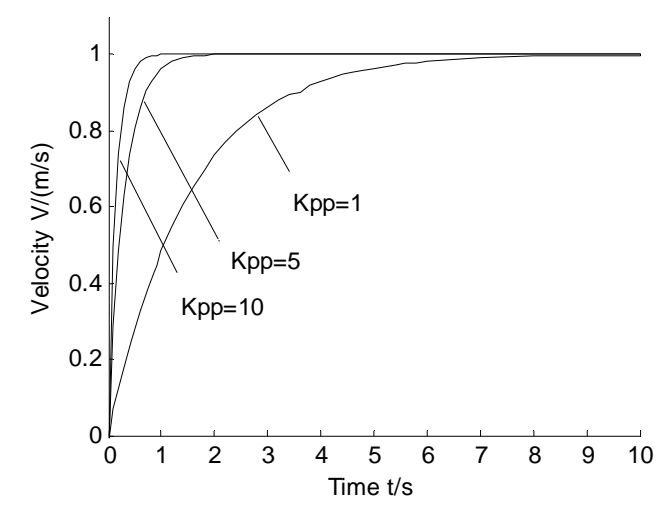

Figure 9. The influence of position loop gain on feed system

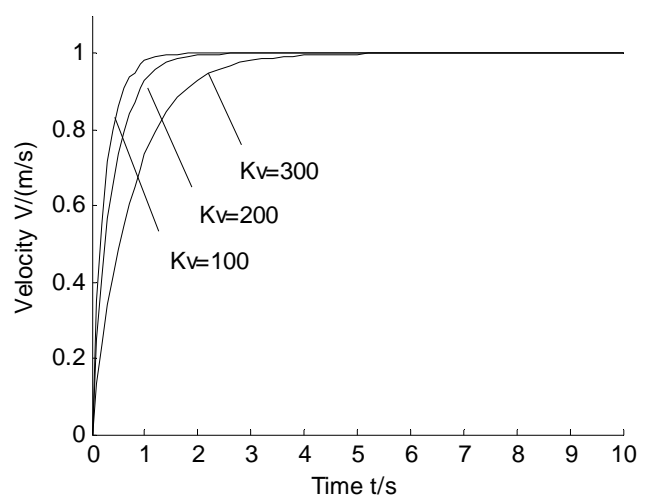

Figure 10. The influence of the speed adjustment gain on the feed system

\section{Conclusions}

Considering the factors such as bearing friction of rail and interstice, a perfect biaxial coupled feed system model is established for the feeding system of vertical machining center with closed loop control. Through the simulation analysis of the Y-axis feed system of the machining center, it is concluded that the weight of the spindle box, the output torque of the servo motor, the position loop gain and the speed loop gain have important influence on the dynamic characteristics of the feed system. The position parameters of the spindle box have little effect on the dynamic characteristics of the feed system. However, the influence of the position parameters of the spindle box on the feed system should be taken into account in the design of the precision machine tool feed system.

\section{Acknowledgements}

This project is supported by the National Science and Technology Major Project, China (No. 2012ZX04005-021)

\section{References}

[1] L L Liu, H Z Liu, Z Y Wu, et al.: Transactions of the Chinese Society for Agricultural Machinery, Vol. 41 (2010) No.11, p.212. (In Chinese)

[2] Ebrahimi M and Whalley R.: Computers \& Industrial Engineering, Vol. 38 (2000) No.1, p.93.

[3] Y X Li, W H Zhao and Y Cheng: Journal of Xi'an Jiaotong University, Vol. 46 (2012) No.4, p.119. (In Chinese)

[4] L M Xie, X Y Yang and L Jin: Modern Manufacturing Engineering, (2016) No.1, p.82. (In Chinese)

[5] C S Guo, Z Y Rui and J Liu: Modular Machine Tool \& Automatic Manufacturing Technique, (2012) No.6, p.5. (In Chinese) 
[6] X H Ding, J T Yuan, Z H Wang, et al.: Modular Machine Tool \& Automatic Manufacturing Technique, (2014) No.3, p.26. (In Chinese)

[7] Garciaherreros I, Kestelyn X, Gomand J, et al.: IEEE International Symposium on Industrial Electronics. IEEE, Vol. 41 (2010) No.11, p.131. (In Chinese)

[8] Hsieh M F, Yao W S and Chiang C R: The International Journal of Advanced Manufacturing Technology, Vol. 34 (2007) No.9, p.933.

[9] W Y He: Research on the Technology of Double Axis Synchronous Control for CNC Machine Tools (Huazhong University of Science and Technology, China 2011). (In Chinese)

[10] THK. A Interpretation of Linear Motion System.

[11] Harris, T. A., Kotzalas, M. N.: Analysis of Rolling Bearing(China Machine Press, China 2009). (In Chinese) 